\title{
MODO DE VIDA E RELAÇÃO MÃE CRIANÇA: UM ESTUDO DO ANDAR*
}

\section{WAY OF LIVING AND MOTHER-CHILD RELATIONSHIP: A STUDY ON WALKING}

\author{
Elaine Pedreira Rabinovich ${ }^{1}$ \\ Ana Maria Almeida Carvalho ${ }^{2}$
}

RABINOVICH, E.P.; CARVALHO, A.M.A. Modo de vida e relagao mae-crianga: um estudo do andar. Rw. Bras. Cresc. Desenv. Hum., Sao Paulo, 11(1), 2001.

Resumo: A idade da marcha independente de 60 criangas paulistanas de $\mathrm{O}$ - 12 anos foi analisada com relaçao a alguns aspectos da organiza ao física e psicológica do ambiente doméstico: presença/ausência de condições físicas e condições controladas pela mãe favorecedoras de comportamentos exploratórios infantis (autonomia). Propõe-se um esquema de análise no qual os conceitos de apego e autonomia, relativos à relação mãe-criança, são associados aos de "lugar" e "espaco", relativos a organização do ambiente doméstico; ambas dimensões são compreendidas como expressão de um "sistema de desenvolvimento" que inclui a organização psicológica da díade mãe-criança e sua suscetibilidade ao sistema de crenças e as condições de vida concretas nas quais o desenvolvimento ocorre. Uma comparação com as práticas de criação e a organização ambiental numa sociedade de caça-coleta (!Kung) e usada para realçar o conceito de sistema de desenvolvimento.

Palavras-chave: modo de vida; relação mãe-criança; andar independente.

\section{INTRODUÇÃO}

O objetivo deste trabalho é analisar aiguns aspectos do contexto em que o desenvolvímento da criança ocorre, e verificar as implicações deste contexto sobre o desenvolvimento, especificamente sobre a marcha.

Este objetivo originou-se de uma pesqui$\mathrm{sa}^{3}$ que visou analisar métodos e instrumentos e desenvolver propostas operacionais de acompa- nhamento do desenvolvimento geral infantil em nível institucional. Sua população foi de crianças na faixa etária de 0 a 2 anos, residentes no subdistrito de Vila Madalena, São Paulo, inscritas no programa de Saúde da Criança do Centro de Saúde Geraldo Paula Souza.

O pressuposto teórico de tal pesquisa foi o de que o desenvolvimento ocorre na interação entre aspectos biológicos e contextuais, considerados material, social e relacionalmente.

* Este trabalho é parte da dissertação de mestrado: Rabinovich, EP. Modo de vida e relação mãe-criança: o mamar e o andar o modo de morar e o modo de dormir. São Paulo, 1992. Instituto de Psicologia, Universidade de São Paulo. Orientador: Ana Maria Almeida Carvalho. Bolsa CAPES. Agradecimentos às Profas. Dras. Emma Otta, Vera Bussab e Nielsy Bergamasco, cujos ensinamentos basearam este trabalho.

1 Centro de Estudos do Crescimento e Desenvolvimento Humano/Faculdade de Saúde Pública-USP; Laboratório de Psicologia Sócio-Ambiental e intervenção- LAPSI/lnstituto de Psicologia-USP. Apoio Fapesp.

2 Instituto de Psicologia-USP. Pesquisador-bolsista do CNPq/apoio FAPESP. Correspondência para: Elaine Pedreira Rabinovich Rua Maranhão, 101 ap. 101 CEP 01240-001 - São Paulo - SP. elainepr@clas.com.br

3 Estudo de Métodos e Intrumentos para Acompanhamento de Desenvolvimento em Unidade de Saúde. Elaine Pedreira Rabinovich, Denise Cristina de Oliveira, Neusa Guaraciaba dos Santos. Orientador: Prof Dr. Arnaldo Augusto Franco de Siqueira. Agência Financiadora CNPq. 
Em função desta premissa, a pesquisa foi realizada através de visitas domiciliarem, em que se procurou estudar a criança e seu "habitat natural".

A visita domiciliar desvelou que, ao lado de fatores sócio-econômicos, há estilos ou modos de vida que caracterizam cada família. A confrontação direta com o modo de vida e os habitats das crianças e de suas famílias recrudesceu o ponto de vista de que comportamentos legitimados socialmente são percebidos como "normais”, ou seja, de que o ponto de vista do pesquisados é uma fonte de viés etnocêntrico. Conforme KON (1987), é difícil distinguir entre processo de determinação, motivação e legitimação, havendo geralmente redução do primeiro ao último. Esta constatação nos levou a sentir a necessidade de ampliar o referencial de análise através de uma abordagem comparativa.

Alguns pesquisadores (KONNER, 1972/ 1981) desenvolveram a convicção de que certas contribuições para compreender a infância viriam de, e talvez apenas de, estudos interculturais e interpopulacionais. PARKE, GROSSMANN \& TINSLEY (1981) sugerem que a razão para se engajar em uma pesquisa intercultural é ser capaz de variar sistematicamente fatores que não podem ser variados dentro de uma única população ou sistema cultural. CARVALHO (1989) considera que o estudo comparativo é útil para a formulação de princípios gerais de comportamento devido quer às semelhanças quer às diferenças por ele evidenciadas.

Estudos comparativos podem ir tanto na direção dos antepassados, quanto na de outros primatas, ou na de povos modernos em contextos sócio-culturais e históricos diversos.

Neste trabalho, propõe-se analisar os dados obtidos a respeito das crianças de Vila Madalena cotejando-os com dados relativos a crianças da cultura !Kung.

Os !Kung (ou !Kung San) são um povo moderno, nómade, que vive no deserto do Kalahari, no Sudeste da África, em um modo de vida de caça e coleta. Estão nessa região há 50.000 anos. Segundo De^VORE \& KONNER (1974, p.23) “os San não são apenas diferentes de nós; são representativos do modo de vida em que o homem e as relações mãe-filho humanas evoluíram”. "Eles são seres humanos modernos cujo estilo de vida tem suas raízes ligadas às origens da humanidade” (LEAKEY \& LEWIS, 1981/ 1988, p.90). Segundo CARVALHO (1989), o conhecimento do "ambiente específico da espécie”, ou seja, o ambiente no qual estão presentes as pressões seletivas responsáveis pela evolução de suas formas características de adaptação, oferece pistas sobre o funcionamento e o desenvolvimen- to do organismo adaptado. Considerado sob este aspecto, este estudo propõe, parafraseando BLURTON JONES (1972/1981), descrever os contextos de desenvolvimento nos quais o sistema de desenvolvimento característico da espécie está funcionando, e as conseqüências dessa interação sobre esse mesmo sistema.

O conceito de “contexto” é aqui tratado como "modo de vida", especialmente em seus aspectos imediatos (microsociais): o modo de morar e de dormir e a relação mãe-criança. O modo de vida é um constructo sócio-histórico, utilizado pela etnologia (KON, 1987). Significa que se considera a totalidade das formas historicamente desenvolvidas e interrelacionadas, assim como os modos das atividades sociais -- trabalho, lazer, padrões de relacionamentos interpessoais, etc., típicos de uma dada sociedade, em sua unidade com a estrutura social e o estilo predominante de pensamento. “As idéias, ações, valores, hábitos e crenças de outras pessoas são parte do rico complexo de influências desenvolvimentais a partir das quais as vidas são construídas” (OYAMA, 1989, p. 24).

A exploração, um conceito complementar ao de apego, corresponde a um "sistema comportamental que capacita o indivíduo a interagir com o ambiente, a adquirir informação, e a construir sistemas de conhecimento" (KELLER, 1998, p. 455). Após dominar a primeira tarefa desenvolvimental de estabelecer o apego emocional com os cuidadores primários, a criança tem o desafio de adquirir competência no meio físico. O comportamento exploratório pode ser visto como um sistema geneticamente baseado, tendo a curiosidade como fundamento, que se manifesta, primeiramente, através da exploração proximal, como atenção visual, auditiva, posteriormente complementada pela exploração distal e verbal.

Ao invés de uma sequência filogeneticamente determinada, o desenvolvimento pode ser melhor conceitualizado como uma paisagem mutante de padrões, cuja estabilidade depende não apenas do status orgânico da criança, mas também de sua história experiencial, e como estas interagem com a tarefa particular em questão (THELEN, 2000, p. 393).

O conceito de exploração ativa é fundamental para a compreensão da regulação pelo outro e para a auto-regulação. Ele se refere à atividade motora de um indivíduo e à extensão na qual decisões sobre onde explorar são feitas pelo indivíduo ou guiadas por outras pessoas. As crianças usam as ações para informar a percepção, primariamente através do uso de movimentos exploratórios (GIBSON, 1988, apud Thelen, 2000). 
Para THELEN (2000), o curso desenvolvimental do sistema nervoso pode ser moldado pela natureza do corpo e como ele se move (p. 388), devido ao próprio movimento "instruir" o sistema nervoso, que não pode ser ensinado mas apenas "reunido" pela experiência (p. 389).

A partir desta concepção, a unidade de estudo do desenvolvimento deve ser o sistema formado pelo contexto do desenvolvimento e o próprio desenvolvimento, que é denominado aqui "sistema de desenvolvimento".

\section{Sistema de desenvolvimento e contexto de desenvolvimento}

A noção de sistema de desenvolvimento é uma contribuição da Teoria Geral dos Sistemas aplicada ao estudo do desenvolvimento da criança. Sistema de desenvolvimento "é um conjunto móvel de influências e entidades interatuantes. Inclui todas as influências sobre o desenvolvimento, em todos os níveis de análise” (OYAMA, 1989, p. 26).

Segundo a Teoria Geral dos Sistemas (VON BERTALANFFY, 1968/1977), todo ser vivo é um sistema - um conjunto de elementos em interação; um sistema aberto, capaz de automanutenção, auto-regulação, auto-reprodução e auto-organização. Sistemas biológicos têm as propriedades do todo e da ordem e assim, embora divisíveis em sub-sistemas, não podem ser compreendidos por uma redução de componentes complexos a componentes simples. O desenvolvimento de sistemas vivos envolve diferenciação progressiva, propriedades emergentes, organização, retroalimentação, transações hierárquicas e eqüifinalidade. Eqüifinalidade é a propriedade dos sistemas abertos pela qual seu estado está determinado pela natureza de suas relações, e não por suas condições iniciais, de tal forma que diferentes condições iniciais podem levar a um mesmo estado do sistema (BERENSTEIN, 1978/1988). Conceitos como ordem, desordem, auto-organização, autonomia e complexidade visam fornecer um "novo paradigma" (DUPUY, 1990) que supere a visão positivista, mecanicista, reducionista e linear (KAPLAN \& KAPLAN, 1991), e as dicotomias corpo-mente, inato-aprendido, "nature-nurture", preformismo-construtivismo, evolução-desenvolvimento.

OYAMA (1989) propõe que genes e ambiente sejam considerados parte de um sistema de desenvolvimento que resulta em uma natureza fenotípica. Para ela, a natureza não é transmitida, e sim construída; é um produto do desenvolvimento, o ambiente sendo tão constitutivo quanto os genes. Genes e ambiente social são interagentes herdados, e sistema nervoso e capacidades sociais são produtos do desenvolvimento.
O sistema de desenvolvimento inclui todas as influências sobre o desenvolvimento, em todos os níveis de análise. Os níveis podem ser: célula, órgão, organismo, grupo, organização, sociedade, sistemas supranacionais (MILLER \& MILLER, 1982). Sistemas de desenvolvimento são hierarquicamente organizados e podem ser estudados em cada um desses níveis, sendo que as interações entre os níveis são cruciais (OYAMA, 1989). Segundo esta autora, o que passa de uma geração para outra é um sistema total de desenvolvimento, no qual a natureza (nature) é um produto do processo de interações que chamamos criação (nurture). O conceito de sistemas de desenvolvimento evolutivos fornece uma visão unificada do desenvolviinento, integrando-o à evolução. A hereditanedade não estaria limitada aos genes, mas incluiria aspectos do entorno relevantes para o desenvolvimento. A hereditariedade, pois, não seria atomística, mas sistemática e interativa. A própria evolução seria uma questão de contextos de desenvolvimento que mudam, de tal modo que não se pode compreender a evolução sem o contexto e, ao mesmo tempo, a história evolutiva ajuda a compreender o contexto.

Para LEVINE (1977), os ambientes das crianças são modelados por valores culturais, não apenas específicos a situações de cuidados infantis, mas também derivados de amplas orientações (referentes a relações interpessoais, aquisição pessoal, solidariedade social) associadas aos sistemas sociais e às metas individuais. A função atribuída a tais valores na educação infantil seria a de preparar o indivíduo para participar do sistema em que irá viver.

O contexto (ZASLOW \& ROGOFF, 198l) deve ser visto como uma variável que merece estudo por si só, quer como um determinante de comportamento quer como um aspecto da atividade observada. Por exemplo, CHISHOLM (1981), estudando crianças, Navajo e anglo-americanas, concluiu que o principal detenninante de diferenças interculturais ou intraculturais de padrões de interação mãe-criança eram diferenças na oportunidade de cada criança de interagir com outros além da mãe. Tais diferenças estavam baseadas nos contextos sociais dos grupos residenciais das crianças, onde havia diferenças significativas quanto ao número, idade, sexo e parentesco/familiaridade de co-residentes. Conclui, além disso, que focalizando-se o contexto microsocial é possível relacionar as diferenças e semelhanças observadas inter e intra-grupos aos fatores mais amplos - históricos, econômicos e ecológicos - que determinam em grande parte a natureza e a composição desses contextos sociais através de seus efeitos sobre as atividades de sub- 
sistência, a carga de trabalho, a divisão sexual do trabalho, as rotinas cotidianas, etc. Este estudo ilustra o que aqui estamos entendendo por contexto e sua imbricação no sistema de desenvolvimento.

O sistema de cuidados é o conjunto total das ações de quem cuida sistematicamente de quem é cuidado. Ele faz parte do sistema geral de crenças. O sistema de crenças está enraizado tanto no sistema cognitivo quanto no afetivo (LEWIS \& BAN, 1977) e é parte das características do modo de vida, segundo KON (1987). O sistema de cuidados pode ser um modo mais adequado de agrupar os comportamentos maternos do que o estudo de comportamentos específicos.

Duas vertentes comportamentais impuseram-se ao serem comparadas às populações de Vila Madalena e os !Kung: o sistema de aleitamento e o sistema de locomoção.

A locomoção estaria ligada ao modo de lidar com a autonomia, independência ou exploração, sendo um conceito em certa medida complementar ao de aleitamento. Enquanto no aleitamento estão supridas necessidades ligadas ao apego (ou dependência), na autonomia estão sendo supridas necessidades ligadas à exploração (ou independência).

Esses dois sistemas podem ser pensados como o núcleo central da relação mãe-criança, em torno do qual se estrutura o desenvolvimento da criança.

Enquanto o sistema de aleitamento é o modo como a mãe se põe à disposição do filho, o sistema de locomoção é o modo como ela põe o mundo à disposição da criança. A autonomia resulta tanto da mãe permitir o movimento da criança em direção ao mundo quanto ao modo como a mãe se retira e deixa a iniciativa das ações à criança. A locomoção, portanto, neste sentido mais amplo, implica o acesso ao mundo.

O sistema de locomoção pode ser observado diretamente ou inferido da fala materna, significando a possibilidade de liberdade da criança. Conforme BRAZELTON (s.d./1987), a mãe que permite à criança olhar em torno enquanto é amamentada ao seio já indicaria como lida com a necessidade de autonomia de seu filho.

Há culturas, como a Zinacanteca (BRAZELTON, s.d./1987) que não valorizam a autonomia, que não é permitida nem esperada. Nessa cultura, os bebês são mantidos amarrados, em quartos obscurecidos e sem estímulos, sendo tocados apenas quando alimentados ou banhados. Trata-se de uma sociedade estável, em que as distâncias sociais são mantidas idênticas através das gerações, e nas quais se espera submissão às normas vigentes.
No conceito de sistema de locomoção está implícito um valor. Através da locomoção, a mãe permite o acesso à exploração do mundo, dos objetos e de si próprio, e fornece as condições para que isso ocorra. Trata-se de uma dimensão potencial, além da realidade imediata, do que poderia ser denominado "espaço potencial de desenvolvimento”.

TUAN (1977/1983) propõe os conceitos de Espaço e Lugar. O “lugar”, para esse autor, é segurança, enquanto espaço é liberdade. “Os lugares são centros aos quais atribuímos valor e onde são satisfeitas as necessidades biológicas de comida, água, descanso e procriação” (p. 4). O espaço é experienciado quando há lugar para se mover (p. 13). A espaciosidade está ligada à sensação de ter espaço, de estar livre (p. 5). "Liberdade implica espaço: significa ter poder e espaço suficientes em que atuar. O oposto da espaciosidade é o sentimento de apinhamento” (p. 60).

Os conceitos de lugar e espaço parecem equivalentes às necessidades supridas pelo apego e às necessidades supridas pela locomoção. O "lugar" original da criança pode ser pensado como o útero materno, posteriormente o corpo materno e, finalmente, a representação simbólica e vivenciada de um lugar protegido no mundo; em certo sentido, do “si próprio”, do corpo como a casa de si próprio. A locomoção pode ser pensada como a geratriz de sensações de poder de ação, de potência.

\section{Aspectos evolutivos e históricos da relação mãe-criança}

O ambiente (contexto) atual da vida humana é muito diferente daquele em que se processou a maior parte da história evolucionária e a constituição das características básicas da espécie, e que se caracterizava por um modo de vida de caça e coleta (LEAKEY \& LEWIS, 1981/ 1988). Mesmo no caso dos !Kung, não se pode afirmar que vivam exatamente no mesmo "ambiente evolucionário” de seus antepassados, porque foram sendo forçados a se retirar para áreas mais desérticas pelos invasores holandeses, além de que há, atualmente, um movimento em direção à sedentarização (LEAKEY \& LEWIS, 1981/ 1988). Mas, segundo CARVALHO (1989), é útil considerar as exigências adaptativas daquele modo de vida para se compreender o comportamento humano, já que o Homo sapiens de hoje é, biologicamente, a mesma espécie que já existia há pelo menos 50 mil anos, e que veio se constituindo ao longo de pelo menos dois milhões de anos, ainda que nos últimos dez mil anos, desde o surgimento da agricultura, o modo de vida da espécie tenha se alterado de forma acelerada. 
Teria havido dois momentos decisivos na evolução do ser humano: a postura ereta e a comunicação verbal.

Com a postura ereta, três ou quatro milhões de anos atrás, ocorreram modificações essenciais no que se refere quer ao próprio curso da hominização, quer da relação mãe-criança: a liberação das mãos, e o estreitamento da cintura pélvica.

A liberação das mãos permitiu o fazer, o tocar, o agarrar, o atirar, e principalmente, no que se refere à relação mãe-criança, o carregar. Os primatas têm mãos que, sob o controle do feedback do olhar, realizam uma grande quantidade de manipulações que outros animais realizam com a boca (HOCKFTT, 1960). Diferentemente dos demais primatas, nos quais o filho se agarra à mãe, a perda dos pelos do corpo obrigou a mãe humana a carregar ativamente o seu filho (MELLEN, 1981).

Concomitantemente à posição ereta, ocorreu um desenvolvimento cerebral retroalimentado pelo exercício manipulatório e retroalimentador deste. Para LEAKEY \& LEWIS (1 981/1988), o tripé sobre o qual se deu a evolução humana foi o uso cada vez mais complexo de instrumentos, a rede social também cada vez mais complexa, e a comunicação verbal possibilitando essa complexificação. Esse é o sentido da afirmação de que o homem é um “animal cultural”, pois a interação social e a inovação tecnológica acabaram por constituir pressões seletivas para a evolução dos hominídeos.

Em termos biológicos, ocorreu o aumento do volume cerebral, com diferenciação de funções. Ao lado desse aumento, em conseqüência da postura ereta, houve um estreitamento da cintura pélvica, necessário para a movimentação das fêmeas. Em função dessas modificações, o crescimento cerebral teve que se dar fora do útero, o que acabou por determinar o nascimento de bebês humanos vulneráveis, em estado embrionário, comparativamente aos outros primatas (GOULD, 1977/1987). Estas circunstâncias favoreceram, e foram retroalimentadas pelo desenvolvimento da sociabilidade e por um longo período de aprendizado (LEAKEY \& LEWIS, 1981/ 1988).

A família humana surgiu provavelmente com o Homo erectus, entre um milhão e seiscentos a quatrocentos mil anos atrás. Este Homo domesticou o fogo. WASHBURN \& LANCASTER (1975) supõem que a família monogâmica já existia no tempo do Homo erectus, e que o desaparecimento do estro da fêmea foi essencial para essa forma de organização. MELLEN (1981) supõe que um macho adulto era necessário para cuidar das crianças, além da mãe, no ambiente de savana onde ficavam expostos a perigosos predadores durante o Plio-pleistoceno. Para este autor, a divisão do alimento nos acampamentos ("home bases”) através da diferenciação de papéis a partir da divisão de trabalho - caça e coleta forneceu a base do amor e das relações sociais em geral.

WASHBURN \& LANCASTER (1975), pensando no Homo erectus como caçador coletor, também supõem que a reciprocidade econômica (troca de alimentos entre indivíduos), que não existe entre primatas, criou um novo conjunto de vínculos interpessoais. Se os machos caçam e as fêmeas coletam, e os produtos são trocados e dados aos filhotes, isto pode ter se tornado a base da família humana. MELLEN (1981), contudo, acredita que há outras causas, além das econômicas; supõe que as mesmas pressões que favoreceram trazer o alimento para ser dividido no grupo favoreceriam o aparecimento do amor no sentido de potencialidade afetiva. Conclui este autor que na ligação emocional macho-fêmea, tanto quanto no desenvolvimento posterior do afeto paterno, o ponto biológico vital foi a sobrevivência da criança proto-humana, sendo esta a razão primária pela qual homens e mulheres têm a tendência de se amarem.

A sobrevivência da criança depende da proteção dos pais. BOWLBY (1969/1981) sustenta que a função biológica básica do apego mãe-criança foi a proteção contra predadores. A relação mãefilho seria o fruto de pressões seletivas presentes no ambiente evolucionário da espécie que geraram a necessidade de mecanismos que garantissem a proximidade adulto-criança como forma de proteção do bebê.

O modelo de criação que decorre desta concepção a partir das condições de evolução humana implica em contato constante entre a mãe e a criança, alimentação contínua e proximidade a fim de garantir uma base segura para a exploração.

Esta concepção contrasta com a que é sustentada por historiadores e outros cientistas humanos. Historicamente, do modo de vida de caçacoleta até hoje, profundas alterações ocorreram, e seriam os determinantes dos sistemas de criação. Segundo BADINTER (1985), por exemplo, no século XVIII a amamentação era considerada ridícula e repugnante nas classes mais altas, não havendo apego materno, que seria fruto de um mito destinado a conservar a mulher em uma posição de inferioridade ante o homem.

Para ARIÈS (1973/1978), é a partir do século XVII que começa uma preocupação com a infância, surgindo concomitantemente o sentimento de família. POSTER (1978/1979) comenta que o que caracteriza a família moderna, em contra- 
posição a épocas anteriores, é a sua centração nas crianças.

Segundo a visão histórica, a relação mãecriança é permeada por questões econômicas, políticas e culturais. Os cuidados com a criança não se dariam de modo constante através da história, dependendo da ideologia sobre a relação mãecriança, da concepção sobre o que é a criança, do(s) papel(eis) que a mulher desempenha na sociedade e das condições gerais do modo de vida.

O modelo de criação depreendido da visão histórica é que a relação mãe-criança é substituível por qualquer outra, que a amamentação é um costume errático, que a “ideologia” determina modos de vida e modos de criar, que o vínculo mãe-criança e o afeto são mitos modernos.

Contudo, recentemente, um outro personagem entrou em cena, trazendo novas informações sobre a questão da relação mãecriança.

\section{O "elo perdido"}

O “elo perdido” é o próprio bebê, que apenas recentemente aparece como personagem de estudos e pesquisas, e passa a ser considerado e a atuar como ator principal, não mais como mero apêndice a reboque de outros personagens.

Novos métodos de investigação, de cerca de quinze anos para cá, têm revelado o bebê como um ser competente para sobreviver. O bebê, considerado frágil e desamparado, tem-se revelado ativo em sua capacidade de perceber, comunicar, interpretar e expressar emoções, e de as regular durante interações sociais. Sua fragilidade orgânica teria sido complementada por atributos comportamentais e interacionais, de modo que o bebê nasce equipado pela pressão evolutiva de forma a garantir que o adulto se apegue a ele. A neotenia, tendência evolutiva da qual resultou a forma infantil do bebê humano, assim como de outros mamíferos e aves, possibilitou estímulos que são propostos como mecanismos liberadores para o comportamento parental (KONNER, 1977b). Sua universalidade ajudaria a explicar o potencial para a adoção de espécimes jovens, inclusive o afeto humano por bebês de outras espécies (cãozinho, gatinho etc.).

Do ponto de vista motor, reflexos como os de agarrar (BLURTON JONES, 1972/1981), sucção, busca e preensão do seio, estão intimamente associados ao contato do bebê com a mãe, constituindo parte do sistema de nutrição via aleitamento e da própria comunicação do bebê (WIDMER, 1987).

O neonato reconhece e prefere a face materna (FIELD, COHEN, GARCIA \& GREENBERG, 1984; BUSHNELL, FAI \& MULLIN, 1989), distingue e prefere a voz materna (De
CASPER \& FIFER, 1980), prefere o tom de voz "infantilizado" com que geralmente o adulto, preferencialmente a mulher, e preferencialmente a mãe, se dirige a ele, conhecido como "baby-talk" (FERNALD, 1985); discrimina e prefere o odor axilar da mãe quando alimentado ao seio, e, com seis dias apenas, apresenta uma resposta diferencial para o cheiro do leite da própria mãe (CERNOCH \& POSTER, 1985). Além disso, discrimina e prefere certas cores a outras (BORNSTEIN \& MARKS, 1982), discrimina e prefere certos sons a outros (GOTTLIEB, 1985; KLAUS \& KLAUS, 1986/1989), assim como odores (RIESER, YONAS \& WIKNER, 1976) e sabores (BERGAMASCO \& BERALDO, 1990).

Todo este equipamento perceptivo do bebê tem o sentido de facilitar a sua interação e adaptação ao meio humano onde vive. É através desse meio que ele poderá exercitar e desenvolver suas habilidades.

PAPOUSEK \& PAPOUSEK (1984) verificaram a sincronia na comunicação materno-infantil, no que denominaram "espelho biológico" ou "eco biológico". Esta sincronia se carateriza pela fala tipo "baby-talk", expressões faciais e movimentos corporais de mãe e criança, como se estivessem envolvidos numa dança. Estes autores observaram igualmente que os padrões de fala, orientação e movimentos corporais são altamente adaptados para a competência cognitiva, de aprendizagem, e de processamento de informação da criança, constituindo-se num forte apoio para seu desenvolvimento cognitivo; ou seja, o modo como a mãe se comunica fornece o meio através do qual a mensagem pode ser apreendida, constituindose, por si só, na própria mensagem. Segundo TREVARTHEN (1979), esta comunicação é o principal fator na criação do elo mãe-filho.

Deste modo, haveria facilitadores para a vinculação do bebê ao que se convencionou chamar figura de apego. A necessidade de apego seria uma necessidade primária, como fome, sede ou sexo (BOWLBY, 1969/1981) e seria responsável pela segurança básica, ou, como diz ERIKSON (1963/1976), pela capacidade de confiar em si e no outro, além de proporcionar à criança uma base segura a partir da qual poderia explorar o seu meio exercer sua capacidade de locomoção e conseqüente autonomia - e retornar a ela em caso de perigo.

Podemos concluir que o aparelho psíquico e perceptivo do neonato demonstra uma prontidão para relacionar-se com outras pessoas, especialmente com sua mãe, assim como há uma complementaridade materna à estimulação fornecida pela criança. A pressão evolutiva favoreceu o vínculo mãe-criança, colocando à disposição de am- 
bas os equipamentos e habilidades necessários para isto. A cultura, no entanto, opera segundo forças ditadas por conjunturas diversas, e estas oscilam em grandes arcos pendulares, num tipo de equilíbrio dialético, ora favorecendo o vínculo mãe-criança, ora não o favorecendo, ou modificando-o, ora fazendo ambos concomitantemente: a situação da mulher moderna cosmopolita da sociedade atual.

A flexibilidade adaptativa do homem permite-lhe sobreviver em condições bem diversas. Conforme BLURTON JONES (1972/1981), a existência de adaptações a um tipo de prática de criação não implica necessariamente conseqüências prejudiciais em decorrência do desenvolvimento sob condições diferentes; implica, sim, que uma criança criada de forma “errada” estará mal adaptada ao ambiente em que o sistema em questão evoluiu. "A presença de adaptações a um certo tipo de criação implica que este é o contexto de desenvolvimento ao qual todo o sistema de desenvolvimento está adaptado" (BLURTON JONES, 1972/1981, p. 319).

\section{OBJETIVO}

Este estudo visa explorar relações entre modo de vida e desenvolvimento motor. Para isso, estudou o modo de vida de um grupo de crianças de Vila Madalena, São Paulo, usando o modo de vida das crianças !Kung como parâmetro de referência. Estes dois grupos de crianças vivem em condições sócio-econômicas, geográficas, históricas e evolutivas completamente diversas, sendo esta diversidade uma das razões desta proposta. A comparação, evidentemente, deve ser feita com cautela, considerando-se que os dados foram obtidos a partir de métodos e objetivos distintos. Nessas condições, a análise de dados constitui antes um exercício de argumentação e conceituação do que evidência conclusiva a favor destas.

A hipótese que permeia este exercício é a de que, comparando-se dois grupos de crianças, um sem casa, outro do qual se conhecem as casas e famílias, seja possível sugerir como os contextos determinam diferenças no desenvolvimento.

No estudo original, os contextos foram comparados em termos das seguintes variáveis: motivo e idade do desmame; esquema de aleitamento (a pedido ou com horário); presença ou ausência de rotinas; início do sentar sem apoio e da marcha independente, correlacionados com o conceito de autonomia; relações entre o sistema de amamentação e o início da marcha; o quarto de dormir, o berço e suas circunstâncias; o "modo de vida”, entendido a partir do "modo de morar”; paralelos entre o modo de morar, o sistema de cuidados e o desenvolvimento infantil (RABINOVICH, 1992). No presente trabalho focalizaremos dois marcos comportamentais do sistema de locomoção: o sentar sem apoio e a marcha independente.

\section{MÉTODO}

Este estudo está baseado em dois conjuntos de dados: os dados principais que se originaram da pesquisa supra citada e os dados a respeito das crianças !Kung, recolhidos com base em KONNER (1977a, 1972/1981), DeVORE \& KONNER (1974) e LEAKEY \& LEWIS (1981/ 1988).

A pesquisa de Vila Madalena foi realizada no período de julho/1988 a agosto/1989, com um número inicial de 60 crianças de 0 -l ano (35 meninos e 25 meninas), inscritos no Programa de Saúde da Criança do Centro de Saúde Escola Geraldo de Paula Souza da Faculdade de Saúde Pública, São Paulo. Trinta e uma tinham menos de 6 meses (15 dias a 5 meses e 29 dias) e vinte e nove tinham entre seis e 12 meses (de seis meses a doze meses e vinte e nove dias).

A escolha do grupo de estudo foi efetuada após a definição de algumas variáveis de inclusão que buscavam garantir alguma homogeneidade ao grupo. Foram incluídas todas as crianças dentro da faixa etária programada desde que fossem residentes no sub-distrito de Vila Madalena, suas mães ou responsáveis aceitassem participar da pesquisa, e fossem clientes de médico pediatra do Centro que tivesse aceitado participar da pesquisa. Foram excluídas da amostra as crianças que mudaram da área geográfica prevista, as crianças cujas mães ou família solicitaram sair da pesquisa e as crianças que mudaram para um médico não participante da pesquisa.

A maior parte das crianças (45\%) recebeu quatro visitas domiciliares, ao longo de um ano. Trinta e nove crianças (65\%) completaram o período de um ano de observação, com três visitas domiciliares (71.6\%), quatro (58.3\%) ou cinco (13.3\%).

O acompanhamento longitudinal no domicílio utilizou alguns roteiros de observação: Ficha de Acompanhamento de Desenvolvimento do Ministério da Saúde; Procedimento para observação dos “organizadores da psiquê" segundo Spitz; Roteiro para observação do ambiente familiar; Anamnese da criança e da família; Roteiro de entrevista com mães quanto ao sentido atribuído ao desenvolvimento infantil; Roteiro de observação da relação mãe-crianca; Roteiro para 
retorno de Visita Domiciliar (V.D.) ${ }^{4}$. Entre esses dados, foram selecionados para esta análise os relativos à idade do sentar e da marcha independente (tal como relatados pela mãe em entrevista) e aqueles que permitissem classificar a díade mãecriança em termos de autonomia.

As crianças cujas mães impedem ou não facilitam a ação exploratória, assim como a ausência de espaço real foram classificadas como “sem autonomia”. As crianças cujas mães permitem a exploração e propiciam a base concreta para que tal ocorra foram classificadas como "com autonomia”.

Os critérios para definir autonomia passam portanto por dois níveis:

- se a mãe permite ou não a exploração;

- se a mãe possibilita ou não condições para que a exploração ocorra.

Por exemplo: a mãe que deixa sua criança permanecer no berço por longos períodos, sendo este desprovido de mobiles ou brinquedos; a mãe que obriga seu filho a andar calçado com meias no assoalho liso, escorregadio; a ausência de espaço material para a criança brincar e se locomover, etc. indicam ausência de autonomia.

Deste modo, a autonomia é um conceito que é aferido de várias maneiras:

$1^{\circ}$ ) possibilidade da criança se movimentar, agir, brincar, se relacionar, se comunicar, com pessoas e objetos;

$2^{\circ}$ ) criação desta possibilidade através de condições que permitam à criança ter acesso aos objetos/estímulos necessários para que a autonomia se dê.

A pesquisa sobre o modo de vida !Kung foi realizada a partir de levantamento bibliográfico onde foram descritos os seguintes aspectos:

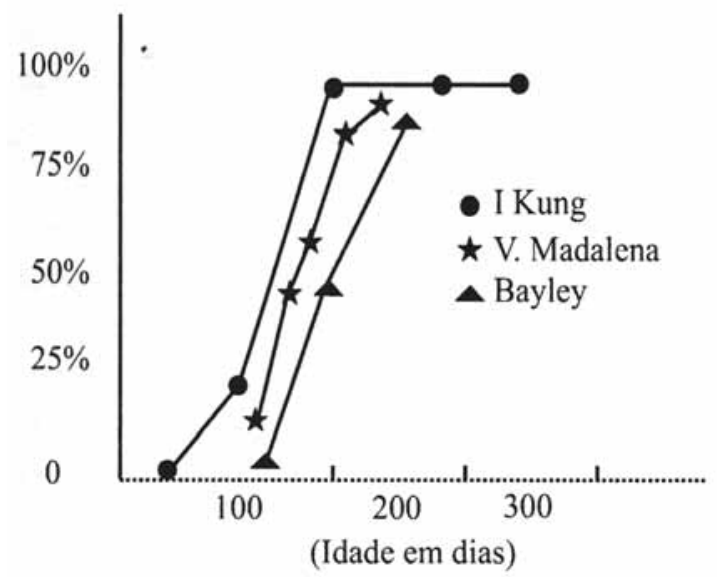

Figura 1. O sentar sem apoio nos grupos de crianças !Kung, Bayley e Vila Madalena, São Paulo, 1991. onde vivem, como vivem, a casa, o que possuem, a organização social, o trabalho, os instrumentos de trabalho, o parto, o sistema de cuidados, o desmame, o sedentarização e suas conseqüências no modo de vida.

\section{RESULTADOS E DISCUSSÃO}

\section{O sentar e a oportunidade}

A Figura l utiliza os resultados referentes ao sentar independente do grupo de crianças !Kung e as normas etárias da escala Bayley conforme KONNER (1977), comparando-os com os dados do grupo de crianças de Vila Madalena. O grupo !Kung era constituído de 21 crianças; o de V. Madalena por 16 crianças, e a escala Bayley se refere a uma amostragern de crianças americanas (apud KONNER, 1977a).

Comparando-se os três grupos, observa-se que as crianças de V.Madalena são um grupo intermediário entre os !Kung e o grupo Bayley. Deve-se ressaltar que o resultado do grupo de V. Madalena é aproximado por ter sido obtido em termos de meses e não de dias e por ter sido a informação obtida a partir do relato materno.

As crianças de V. Madalena podem ser subdivididas em dois grupos quanto ao sentar: 53,3\% sentaram entre 5-6 meses inclusive, e outros $46,7 \%$ entre $7-9$ meses. Pode-se dizer que as que sentaram após os 6 meses o fizeram devido à falta de oportunidade de treino, excetuado um caso de atraso motor por doença grave (leucemia).

A falta de oportunidade se deve ao "modo de vida”. Se às crianças !Kung é permitido viver na posição vertical e permanecerem sentadas ao

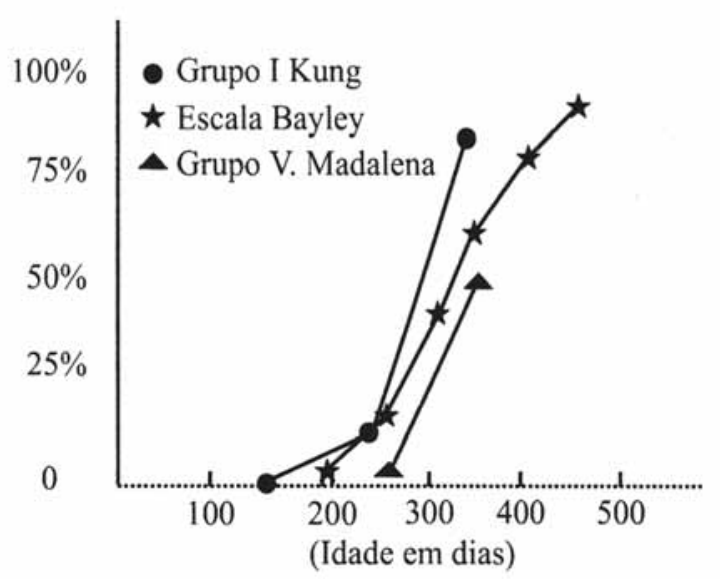

Figura 2. Locomoção ereta (marcha independente) em crianças !Kung, Bayley, Vila Madalena, S. Paulo, 1991.

4 Tais instrumentos e a fonna de analisá-los estão detalhados em Siqueira et al. (1992). 
lado de suas mães, as crianças de Vila Madalena permaneciam deitadas a maior parte do tempo, pois suas mães tinham que desempenhar os afazeres domésticos ou não permitiam o treino por questões emocionais (medo de machucar, por exemplo).

Das oito crianças que sentaram após os sete meses, quatro eram terceiros filhos e dois eram filhos de empregadas domésticas que moravam na casa dos patrões. AINSWORTH (1977) crê que a precocidade das crianças de Uganda por ela observadas resulta do exercício e da estimulação de liberdade irrestrita de movimentos, e de serem carregadas todo o tempo, o que não ocorria com essas crianças de Vila Madalena. De igual maneira, pode-se supor que as crianças que se sentaram mais tardiamente no grupo estudado em São Paulo tiveram menos oportunidade de exercício e de estimulação.

Deste modo, comparando-se os três grupos de crianças, podemos supor que as crianças de Vila Madalena tiveram mais oportunidades para o desenvolvimento motor do que as americanas (conforme a escala de Bayley), e menos do que as crianças !Kung. Parece, portanto, haver um padrão neurológico de maturação que pode ser facilitado ou retardado pela ação do meio.

\section{2. $\mathrm{O}$ andar e a autonomia}

85,7\% (12:14) das crianças a quem a mãe confere autonomia andaram até 13 meses, enquanto $72,7 \%$ (8:11) a quem as mães não deram autonomia andaram após os 14 meses (Fisher, $\mathrm{p}=0,004)$. Pode-se, pois, aventar a hipótese de uma relação entre autonomia e início da marcha.

KONNER (1977) apresentou um gráfico comparando o andar inicial sem assistência (Fase E da escala de Bayley: 3 passos sem segurar a mão, sem a progressão calcanhar - dedos do pé ou com movimentos sincrônicos dos braços) do grupo de crianças !Kung com as normas etárias conhecidas pela escala de Bayley.

A partir de informações obtidas a partir do relato materno sobre o início da marcha independente das crianças de Vila Madalena, acoplandoas ao gráfico apresentado por Konner, obtivemos os resultados descritos na figura 2.

Pode-se observar, novamente, com as devidas ressalvas, que o grupo de Vila Madalena situa-se entre o grupo !Kung e o americano. No grupo de Vila Madalena houve uma subdivisão entre crianças que andam até 13 meses $(15: 25)$ e crianças que andam entre 14-16 mesós (10:25), sendo que $44 \%$ das crianças de Vila Madalena andam até 12 meses contra cerca de $80 \%$ das !Kung que andam antes dos 12 meses. Portanto, pode-se sugerir que mais crianças !Kung iniciam mais cedo a marcha independente do que as crianças de Vila Madalena. Em relação à escala Bayley, parte do grupo de Vila Madalena inicia a marcha antes do marco dessa escala e parte do grupo (40\%) após.

Às crianças !Kung é dada grande autonomia e iniciam a marcha cedo, enquanto as crianças Zinacantecas, estudadas por BRAZELTON (1977) não são reforçadas para vocalizar, sorrir ou no desenvolvimento motor. Essas crianças, mantidas embrulhadas, deitadas, sem oportunidade para exploração visual, tátil, durante os primeiros quatro meses, andam com um mês de atraso em relação às crianças americanas, mantendo esse atraso consistentemente nas várias etapas motoras e cognitivas. O curso do desenvolvimento corre "normalmente atrasado". Conclui o autor que observar o bebê Zinacanteca se desenvolver face à supressão do seu comportamento exploratório acrescenta uma nova dimensão à influência poderosa de maturação do sistema nervoso, confrontado com o estilo de vida americano em que há uma expectativa ansiosa quanto à realização individual. No padrão americano, espera-se que a criança seja independente, automotivada e busque o sucesso, em conformidade com os padrões norte-americanos para os adultos, enquanto na cultura Zinacanteca se espera submissão às normas vigentes.

Pode-se pensar, portanto, que a autonomia, como um valor, influencia o início da marcha, assim como outros comportamentos bem mais complexos do ponto de vista social. Para BRAZELTON (1977), a educação Zinacanteca cria indivíduos sem aparente auto-questionamento e com um tipo de aprendizado por imitação que está adaptado à ênfase cultural na igualdade e na interdependência. SORENSON (1979), estudando a cultura Fore, um pequeno (enclave neolítico em Nova Guiné, conclui que os dois aspectos básicos da aprendizagem e desenvolvimento social das crianças Fore, isto é intensa associação tátil e liberdade para perseguir metas individuais, fornecem a base para tipo cooperativo da organização social Fore, que seja, grupos informais e voluntários, com ausência de chefes, curandeiros ou patriarcas, na quais “a apreciação sóciosensual da excitação e dos valores de vida orientam buscas individualistas dentro de um contexto de indivíduos reciprocamente suportivos” (p. 304).

Com base nesses estudos comparativos pode-se pensar que ao avaliar a idade do início da marcha não estaríamos apenas avaliando um aspecto do desenvolvimento motor, mas um dado "cultural”, profundamente imbricado a outros elementos da cultura.

O modelo de subsistência de caça-coleta origina um aprendizado desde a infancia de com- 
portamentos sociais adequados a ela, tanto para a reprodução, quanto para a produção (DeVORE \& KONNER, 1974). A locomoção independente precoce estaria a serviço da sobrevivência da criança e da liberação parcial da mãe da tarefa de carregá-la nas suas atividade de coleta.

Do ponto de vista do desenvolvimento psiconeurológico, o modo de carregar a criança na bolsa "kaross" colocada lateralmente possibilita uma ampla visão pela criança, não apenas do ponto de vista da mãe quando carregada às costas, e da visão apenas da mãe quando carregada à frente do corpo da mãe, na posição vertical em que a criança é mantida nas longas caminhadas maternas favorece o fortalecimento dos músculos da nuca e o desenvolvimento céfalo-caudal. A organização postural é favorecida pelos estímulos cinestésicos e da equilibração. A liberdade das mãos favorece, coordenação viso-motora. Todos os poucos objetos são colocados à disposição da criança, sem restrições, assim que ela possa manejá-los. Deste modo, um conjunto de fatores diretamente associados ao modo de vida resulta em uma marcha independente precoce.

No caso das crianças da Vila Madalena, os dois grupos associados à presença ou ausência de autonomia indicam que dentro de um mesmo grupo e extrato cultural há diferenças no manejo da autonomia e no início da marcha resultando, provavelmente, em outras diferenças. A forte associação entre início da marcha independente e ter espaço/objetos disponíveis e permitir a exploração indica um sistema de desenvolvimento ancorado em vários pontos: a existência de um espaço de locomoção; objetos que suportem esta locomoção e a orientem; um sistema de crenças parentais que apoie as ações da criança; um conjunto de práticas sócio-simbólicas de cuidados que concretize estas possibilidades.

Deste modo, embora a marcha esteja fortemente associada ao desenvolvimento motor, o modo como a cultura do grupo sóciofamiliar lida com a autonomia influencia o início da marcha independente.

Um estudo recente realizado na cidade de Veneza (MALUCELLI \& MAASS, 2001), enfocando a autonomia fora da esfera doméstica comparando três condições diversas de acesso à rua pelas crianças devido à presença/ausência de carros, apontou que o desenvolvimento da capacidade espacial está associado à possibilidade de locomoção autônoma das crianças pelas ruas, sendo que este acesso dependeria da quantidade de carros circulantes. Conclui que as limitações ao uso do espaço ocorrem concomitantemente a limitações no desenvolvimento infantil. "O confinamento fisico de crianças a áreas limitadas, protegidas e sob a constante supervisão de adultos pode ter uma série de conseqüências sobre várias áreas de desenvolvimento, incluindo a própria satisfação infantil com a sua vida, o bem-estar psicológico, a auto-eficácia, os padrões de sociabilidade e o desenvolvimento cognitivo” (p. 9).

Neste sentido, acreditamos que os nossos dados apontam para essa mesma direção: a de que o acesso ao desenvolvimento motor pode estar associado a áreas múltiplas e crescentemente complexas do desenvolvimento geral.

\section{CONCLUSÃO}

Os sistemas de desenvolvimento, o aleitamento/desmame e a locomoção e aspectos do contexto, podem ser considerados indicadores da relação mãe-criança. Neste sentido, confirmam-se as observações de CHISHOLM (1981), com povos Navajo e Anglo-americano, de que as diferenças observadas inter e intraculturais eram devidas à oportunidade de interação com outras pessoas (família nuclear ou ampliada) e de que essas oportunidades eram uma função do grupo de residência de cada criança. $\mathrm{O}$ grupo de residência, o modo de morar, por sua vez, depende de condições ecosócioeconômicas, do contexto macro-social. Através destes estudos, pode-se começar a entender a intrincada rede de influências co-reguladas que produzem o desenvolvimento.

O presente estudo, contudo, mais abre questões do que as responde. O desenvolvimento é visto como um sistema e como um produto de vários sistemas que atuam em vários níveis. Além disso, ele aparece mais como um processo do que como uma aquisição: desenvolver-se é transformar-se no tempo, desenvolvimento é vida. Como no desenvolvimento a criança se apropria da cultura e a cultura se apropria da criança, o desenvolvimento é a aculturação do ser humano na medida em que o contexto humano é cultura. A própria cultura intermedia relações e transforma estruturas interiores.

Para OYAMA(1989), genes e meio sóciocultural são interagentes herdados e o desenvolvimento é seu produto. As interações emergentes são a própria Vida imersa no "caldo onginal da cultura” que se dá com regulações mútuas, gerando, conforrne MORIN (1973/ 1979), ordem e desordem, estreitamente ligadas, fazendo da vida

5 Tipóia utilizada pelas mães !Kung para carregar seus filhos, feita de pele de animal, colocada lateralmente. 
um sistema de reorganização contínua fundado sobre a lógica da complexidade.

Ao se concluir que a idade em que a cnança anda pode ser um indicador de autonomia e que esta varia em função da organização sócio-cultural e afetiva da família, cria=se um caos no que se refere a marcos comportamentais, escalas, etc. Valores parecem dingir sistemas de comportamentos e os própnos valores parecem ser adaptações ao nicho ecológico transmitidos culturalmente.
Este estudo sugere que a ocupação do espaço através da movimentação estaria associada a um sistema de desenvolvimento em que estariam incluídos a possibilidade de tal movimentação e o incentivo a ela, aspectos estes que decorreriam de um sistema de crenças parentais a respeito não só da educação/cnação da prole mas também da concepção de espaciosidade do grupo sócio-familiar. Sugere, igualmente, que tal associação deveria ser melhor estudada e especificada.

\begin{abstract}
Data on independent walking age of 60 children aged 0-12 months living in the city of São Paulo were cross-analysed with some aspects of the physical and psychological organization of the home enviromnent: presence/absence of physical and of mother-controlled conditions favouring the child's exploratory behaviour. An analysis scheme is proposed in which the concepts of attachment and autonomy, relative to the mother-child relationship, are linked to the concepts of "place" and "space", relative to the organization of the home environment; and both these dimensions are understood as the expression of a "developmental system" including the basic psycho-biological organization of the mother-child dyad and its susceptibility to the belief systems and the concrete living conditions within which development takes place. A comparison with the child-rearing practices and environmental organization in a hunter-gatherer society (the Kalahari !Kungs) is used to highlight the concept of developmental system.
\end{abstract}

Key-words: way of living; mother-child relationship; independent walking.

\section{REFERENCIAS BIBLIOGRAFICAS}

AINSWORTH, M.D.S. (1977). Attachment theory and its utility in cross-cultural research. Em RH. LEIDERMAN, S.R. TULKIN \& A. ROSENFELD (Orgs.), Culture and infancy: Variations in the human experience (pp. 4968). New York: Academic Press.

ARIÈS, P. (1978). História social da criança e da familia. (D. Flaksman, Trad.). $2^{\mathrm{a}}$ ed. Rio de Janeiro: Guanabara. (Trabalho original publicado em 1973).

BADINTER, E (1985). Um amor conquistado: o mito do amor materno. (W. Dutra, Trad.). Rio de Janeiro: Nova Fronteira. (Trabalho original apresentado em 1980).

BERENSTEIN, 1. (1988). Família e doença mental. (A. Friedmann, Trad.). São Paulo: Escuta. (Trabalho original publicado em 1978).

BERLALANFFY, L. V. (1977). Teoria geral dos sistemas. (F. M. Guimarães, Trad.). $3^{\mathrm{a}}$ ed. São Paulo: Vozes. (Trabalho original publicado em 1968).

BERGAMASCO, N. H. R \& BERALDO, K. E. A. (1990). Facial expressions of neonate infants in response to gustatory stimuli. Brazilian Journal of Medical Biology, 23: 245249.
BLURTON JONES, N. (1981). Aspectos comparativos do contato mãe-criança. Em N. BLURTON JONES (Org.), Estudos etológicos do comportamento da criança (pp. 317-340). (E. Otta, Trad.). São Paulo: Biblioteca Pioneira Ciências Sociais. (Trabalho original publicado em 1972).

BOWLBY, J. (1981). Apego. (A. Cabral, Trad.). São Paulo: Martins Fontes. (Trabalho original publicado em 1 969).

BORNSTEIN, M. K. \& MARKS, L.E. (1982). Color revisionism. Psychology Today, 15(1): 64-73.

BRAZELTON, T. B. (1977). Implications of infant development among the Mayan Indians of Mexico. Em P.H. LEIDERMAN, S.R. TULKIN \& A. ROSENFELD (Orgs.), Culture and infancy: Variations in the human experience (pp.151-188). New York: Academic Press.

BRAZELTON, T.B. (1987). O bebê: parceiro na interação. Em T.B. BRAZELTON, B. CRAMER, L. KRETSLER, R. SCHAPPI \& M. SOULE (Orgs.), A dinamica do bebê (pp. 9-23). (D.R. Unikowski, Trad.). Porto Alegre: Artes Médicas. (Trabalho original s.d.).

BUSHNELL, I. W. R., SAI, R \& MULLIN, J. T. (1989). Neonatal recognition of the mother's 
face. British Journal of Developmental Psychology, 7(1): 3-16.

CARVALHO, A.M.A. (1989). O lugar do biológico na psicologia. O ponto de vista da etologia. Biotemas, 2(2): 81-92.

CHISHOLM, J.S. (1981). Residence patterns and the environment of mother-infant interaction among the Navajo. Em T. M. FIELD, A. M. SOSTEK, R VIETZE \& RH. LEIDERMAN (Orgs.), Culture and early interactions. (pp. 320). Hillsdale: Lawrence Erlbaum Associates.

CERNOCH, J. \& POSTER, R. (1985). Recognition of maternal axillary odors by infants. Child Development, 56: 1593-1598.

DE CASPER, A.S. \& FIFER, W.P. (1980). Of human bonding: Newborns prefer their mother's voices. Science, 208: 1174-1176.

DEVORE, 1. \& KONNER, M. J. (1974). Infancy in huntergatherer life: An ethological perspective. Em N. F. WHITE (Org.), Ethology and Psychiatry (pp. 111-141). Toronto: University of Toronto Press.

DUPUY, J.R (1990). Ordem e desordem. Ciência e Cultura, 42(2): 150-160.

EIBL-EIBESFELDT, 1. (1974). The myth of aggressionfree hunter and gatherer society. Em R.L. HOLLOWAY (Org.), Primate agression, territoriality and xenophobia. (pp. 69-82). London: Academic Press.

ERIKSON, E.H. (1976). Infância e sociedade. (G. Amado, Trad.). Rio de Janeiro: Zahar. (Trabalho original publicado em 1963).

FERNALD, A. (1985). Four-month-old infants prefer to listen to motherese. Infant Behavior and Development, 8: 181-195.

FIELD, T.M., COHEN, D., GARCIA, R. \& GREENBERG, R. (1984). Mother -stranger face discrimination by the newborn. Infant Behavior \& Development, 7: 19-25.

GOTTLEB, G. (1985). Critical perceptual dimensions of the maternal voice for human infants. Em B. GOTTLIEB \& N. KRASNEGOR (Orgs.), Measurement of audition and vision (pp. 21-27). New Jersey: Ablex.

GOULD, S. S. (1987). Darwin e os grandes enigmas da vida. (M.E. Martinez, Trad.). Sào Paulo: Martins Fontes. (Trabalho original publicado em 1977).

HOCKETT, C.F. (1960). Logical considerations in the study of animal communication. Em W.E. LANYON \& W.M.TAVOLGA. (Orgs.), Animal sounds and communications (pp. 392430). Washington: American Institute Biological Science.

KAPLAN, M. \& KAPLAN, N. (1991). The selforganization of human psychological functioning. Behavioral Science, 36: 161-178.
KELLER, H. (1998). Exploratory behavior, place attachment, genius loci, and childhood concepts: Elements of understanding children's interactions with their environments. Em G. GORLITZ, H.J. HORLOFF, G. MEY, $\& \sim$. VALSINER. (Eds.), Children, cities and psychological theories. Developing relationships. Berlin: Walther de Gruyter. p.454 68.

KLAUS, M. \& KLAUS, R (1989). O surpreendente recém-nascido. (M.C.G. Monteiro, Trad.). Porto Alegre: Artes Médicas. (Trabalho original publicado em 1986).

KON, I. S. (1987). A sociocultural approach. Em J.H. GEER \& W.T. O’DONOHUE (Orgs.), Theories of human sexuality (pp. 257-286). New York: Plenum Press.

KONNER, M. (1977a). Infancy among the Kalahari Desert San. Em RH. LEIDERMAN, S.R. TULKIN, \& A. ROSENFELD (Orgs.), Culture and infancy (pp. 287-312). New York: Academic Press.

KONNER, M. (1977b). Evolution of human behavior development. Em P. H. LEIDERMAN, S. R. TULKIN, S. R. \& A. ROSENFELD (Orgs.). Culture and infancy (pp. 69109). New York: Academic Press.

KONN ER, M. ( 1981). Etologia de um povo que vive da caça e da coleta. Aspectos relacionados com o desenvolvimento infantil. Em N. BLURTON JONES (Org.), Estudos etológicos do comportamento da criança (pp.295-316). (E. Otta, Trad.). São Paulo: Biblioteca Pioneira de Ciências Sociais. (Trabalho original publicado em 1972).

LEAKEY, R. E. \& LEWIN, R. ( 1988). O povo do lago. (N. Telles, Trad.). Sào Paulo: Melhoramentos. (Trabalho original publicado em 1981).

LEVINE, R. A. (1977). Child rearing as cultural adaptation. Em PH. LETDERMAN, S. R. TULK1N \& A. ROSENFELD (Orgs.), Culture and infancy. Variations in the human experience (pp. 29-48). New York: Academic Press.

LEWIS, M. \& BAN, P. (1977). Variance and invariance in the mother-infant interaction: A cross-cultural study. Em PH. LEIDERMAN, S.R. TULKIN, A. ROSENFELD (Orgs.), Culture and infance. Variations in the human experience (pp. 329-356). New York: Academic Press.

MALUCELLI, E. \& MAASS, A. (2001). The development of spatial abilities: growing up with or without cars. Bulletin of PeopleEnvironment Studies, 18: 6-10.

MELLEN, S. L. W. (1981). The evolution of love. New York: Freeman. 
MILLER, J. C. \& MILLER, J. L. (1982). The earth as a system. Behavioral Science, 27(4): 302-322.

MORIN, E. (1979). O enigma do homem. (F.C. Ferro, Trad.). $2^{\mathrm{a}}$ ed. Rio de Janeiro: Zahar. (Trabalho original publicado em 1973).

MONROE, R. H. \& MONROE, R. L. (1971). Household density and infant care in an East African Society. The Journal of Social Psychology, 83: 3-13.

OYAMA, S. (1989). Ontogeny and the central dogma: Do we need the concept of genetic programing in order to have an evolutionary perspective? Em M.R. GUNNAR \& E. THELEN (Orgs.), Systems and development. The Minnesota Symposium on Child Psychology (Vol. 27, pp. 1-34). New Jersey: Lawrence Erlbaum.

PARKE, R. R, GROSSMANN, K. \& TINSLEY, B. T. (1981). Father-mother-infant interaction in the newborn period: A German-American comparison. Em T.M. FIELD, A.M. SOSTEK, P. VIETZE \& P.H. LEIDERMAN (Orgs.), Culture and early interactions (pp. 95-l 13). Hillsdale, NewJersey: Lawrence Erlbaum.

PAPOUSEK, H. \& PAPOUSEK, M. (1984). Learring and cognitive in the everyday life of human infants. Advances in the study of behavior, 14: 127-163.

POSTER, M. (1979). Teoria crítica da família. (A. Cabral, Trad.). Rio de Janeiro: Zahar. (Trabalho original publicado em 1978).

RABINOVICH, E. R. Modo de vida e a relação mãe-criança. o mamar e o andar, o modo de morar e o modo de dormir. São Paulo, 1992. Dissertaçao (Mestrado) - Instituto de Psicologia da Universidade de São Paulo.

RIESER, J., YONAS, A. \& WIKNER, K. (1976). Radial localization of odors of human newborns. Child Development, 47: 856-859.
SIQUEIRA, A. A. E, OLIVEIRA, D. C., RABINOVICH, E. P \& SANTOS, N. G. (1992). Instrumentos para o acompanhamento e avaliação do desenvolvimento infantil na Atenção Primária à Saúde. Revista Brasileira do Crescimento e Desenvolvimento Humano, 2(2): 59-99.

SORENSON, E. R. (1979). Early tactile communication and the patterning of human organization: a New Guinea case study. Em M. BULLOWA(Org.), Before speech (pp. 289306). Cambridge: Cambridge University Press.

THELEN, E. (2000). Motor development as foundationand future od developmental psychology. International Journal of Behavioral Development, 24(4): 385-397.

TREVARTHEN, C. (1979). Communication and cooperation in early infancy: A description of primary intersubjetivity. Em M. BULLOWA (Org.), Before speech (pp. 321-348). Cambridge: Cambridge University Press.

TUAN, Y.F. (1983). Espaço e lugar. (L. Oliveira, Trad.). São Paulo: Difel. (Trabalho original publicado em 1977).

WASHBURN, S. L. \& LANCASTER, C. S. (1975). Evolution of hunting. Em R.B. LEE \& 1. DEVORE (Orgs.), Man the hunter (pp. 293303). Chicago: Aldini Publishing Company.

WIDNER, C. \& TISSOt, R. (1987). Os modos de comunicação do bebê. As posturas, movimentos, vocalizações. (D.S. Pinheiro \& F. A. Braga, Trad.). Rio de Janeiro: Manole Ltda. (Trabalho original publicado s.d.).

ZASLOW, M. \& ROGOFF, B. (1981). The crosscultural study of early interaction: Implication for research on culture and cognition. Em T.M. FIELD, A.M. SOSTEK, P. VIETZE \& RH. LE, DERMAN (Orgs.), Culture and early interac-tion (pp. 237-256). New Jersey: Lawrence Erlbaum.

Recebido em 05/06/2001 Aprovado em 05/08/2001 